\title{
Animal Health Policy
}

Coen van Wagenberg, Willy Baltussen, and Roel Jongeneel

\subsection{INTRODUCTION}

Infectious diseases of livestock cause loss of production in the animals they affect. The severity of disease, and therefore the degree of economic loss, varies with the nature of the infectious agent and with its interaction with the host. If left uncontrolled, those diseases which are highly infectious spread rapidly and those which cause high levels of mortality or debility in affected livestock can have a severe impact on a country's economy. Examples of such diseases are foot and mouth disease (FMD), African

This chapter is a revision of Fred Landeg, Nick Coulson and Monique Mourits, Chapter 11. Animal health policy. In: Arie Oskam, Gerrit Meester and Huib Silvis (Eds) (2011), EU policy for Agriculture, Food and Rural Areas, Wageningen Academic Publishers.

C. van Wagenberg $\bullet$ W. Baltussen

Consumer and Chain Unit, Wageningen Economic Research, The Hague, The Netherlands

e-mail: coen.vanwagenberg@wur.nl; willy.baltussen@wur.nl

R. Jongeneel $(\bowtie)$

Agricultural Economics and Rural Policy Group, Wageningen University, Wageningen, Gelderland, The Netherlands

e-mail: roel.jongeneel@wur.nl

(C) The Author(s) 2019

L. Dries et al. (eds.), EU Bioeconomy Economics and Policies: Volume I, Palgrave Advances in Bioeconomy: Economics and Policies, https://doi.org/10.1007/978-3-030-28634-7_11 
swine fever (ASF) and avian influenza (AI). More insidious diseases such as bovine tuberculosis and brucellosis cause chronic production losses. Those infectious diseases of animals which can also cause disease in human beings (zoonoses) may have very significant public health implications, for example, salmonellosis (food poisoning) or bovine spongiform encephalopathy (BSE).

In order to control animal diseases and limit their impacts, science has to inform an understanding of infectious agents, how they survive in the environment, their mechanisms of infection, how they produce disease and how they spread. Animal diseases may be spread directly by contact between animals. They may also be spread indirectly on the clothing and footwear of people, vehicles, equipment and feedstuffs which have been contaminated with an infectious agent. Diseases may also be spread by animal products such as meat, meat products, milk, milk products, semen, ova and embryos, which have been either derived from infected animals or contaminated by the infectious agent. Controls are therefore aimed at cutting off these mechanisms of transmission. However, some diseases present particular control problems; for example, FMD may be transmitted through the wind over distances more than 200 kilometres and AI may spread via migratory birds. Other diseases may be transmitted by insect vectors, for example, bluetongue. Some diseases have spillover from wildlife hosts into domestic animals, for example, classical swine fever (CSF) and ASF, where wild boar may provide a reservoir of infection.

From the middle of the nineteenth century, as the understanding of the nature of infectious animal disease and its impact on the economy or on public health grew, so too did efforts to control it, mainly in developed countries. Diseases of concern which were highly infectious or insidious in nature could not be controlled without government intervention, whose objective was to achieve the highest health status of country freedom from disease, eradicating it where possible. Once a control programme was started or disease-free status had been established, prevention of disease introduction became a key policy driver through the imposition of import controls on animals and their products. Animal health controls could therefore act as a barrier to trade.

In the context of the Single European Market and intra-EU trade, there needed to be harmonisation of animal health legislation and standards to facilitate the free movement of livestock and their products which are safe for both consumers and livestock. However, when the European Economic Community (EEC) was established in 1958, the animal health 
status of each of the founding member states, and of those countries of Western Europe that were eventually to form the enlarged EU, varied greatly, as did their approach to control. Initially, member states used their national animal health legislation and controls to guarantee trade in healthy live animals and their products. This required bilateral negotiation where the importing country set the trade requirements. It was therefore possible, under political influence, for veterinary authorities to operate a certain degree of protectionism.

\subsection{The EU Framework for Animal Health}

The diseases that the EU needed to focus on to harmonise the internal market in animals and animal products were essentially those diseases listed by the World Organisation for Animal Health (OIE). The OIE is an intergovernmental organisation set up in 1924 to combat animal diseases on a global basis. It has 182 members (mid-2019), including all EU member states. The OIE develops standards relating to rules that member countries can use to protect themselves from the introduction of diseases and pathogens, without setting up unjustified trade barriers. The OIE originally classified animal diseases into two lists:

OIE List A was defined as those transmissible diseases that have the potential for very serious and rapid spread, irrespective of national borders, that are of serious socio-economic or public health consequence, and that are of major importance in the international trade of animals and animal products;

OIE List B was defined as those transmissible diseases that are considered to be of socio-economic and/or public health importance within countries and that are significant in the international trade of animals and animal products.

These lists still provide excellent working definitions of the rationale for EU intervention, and are reflected to this day in the EU approach to disease control for trade purposes. The OIE standards are recognised by the World Trade Organization (WTO) as reference international sanitary rules for trade under the Agreement on the Application of Sanitary and Phytosanitary Measures (SPS Agreement) (see Chap. 4). In 2004, in order to be in line with the terminology of the SPS Agreement, the OIE moved to a single list by classifying diseases as specific hazards and giving all listed 
diseases the same degree of importance in international trade. In 2019 this list now includes 117 animal diseases, infections and infestations.

As soon as a disease is suspected, the EU requires control measures to be taken against major epidemic diseases or exotic diseases, that is, those diseases not normally present in the EU. These are essentially the former OIE List A diseases (see Table 11.1). In the case of an outbreak of any of these diseases, the animals on the infected holding are killed and their carcasses destroyed. Animals which are believed to have been exposed to infection may also be culled in order to prevent the spread of disease. Emergency vaccination may be used as an adjunct to control, but prophylactic vaccination is not permitted for many of them, since it may hide the presence of disease. The objective of control is to achieve the highest OIE health status of 'Country freedom from disease without vaccination'. For vector-borne diseases such as bluetongue, vaccination is the only effective control once the virus is established in the insect vector.

In the case of an outbreak of exotic disease, the concept of 'regionalisation' is important with respect to intra-EU trade. This means limiting the application of measures to control the disease to a specific area where the disease is known to exist, without applying restrictions on the movement of animals and animal products in the rest of the country. Regionalisation and the application of proportionate risk-based controls should minimise the effects of outbreaks of animal disease on the wider rural economy, where tourism and recreational activities play an important role.

The EU has compulsory eradication and monitoring programmes for diseases already in the Union such as brucellosis and tuberculosis (original OIE List B diseases), which are subject to national control programmes; these may be co-financed by the EU (see below).

Table 11.1 Original OIE List A diseases

Foot and mouth disease

Swine vesicular disease

Peste des petits ruminants

Lumpy skin disease

African horse sickness

Classical swine fever

Bluetongue

Newcastle disease
Vesicular stomatitis

Rinderpest

Contagious bovine pleuropneumonia

Rift Valley fever

Sheep pox and goat pox

African swine fever

Highly pathogenic avian influenza

Source: OIE, https://www.oie.int/animal-health-in-the-world/the-world-animal-health-informationsystem/old-classification-of-diseases-notifiable-to-the-oie-list-a/ 


\subsubsection{EU Decision-Making in Animal Health}

The general framework for EU decision-making has been set out in Chap. 5 , and is essentially the same for animal health policy and legislation. It is worth noting, however, that the EU legislation on animal health was usually adopted by the Council under Article 37 TEU (consultation procedure). This allowed a more rapid response to an emergency disease situation. However, if food safety or human health is concerned, the European Parliament also played already a primary role in the adoption of legislation under Article 152 TEU (co-decision procedure). The Lisbon Treaty, brought into force on 1 December 2009, extends co-decision to all areas of animal health and welfare legislation. Since 2014, the regulatory committee for animal health and welfare is the Standing Committee on the Plants, Animals, Food and Feed (SCoPAFF).

\subsubsection{Third-Country Imports}

Controls over the importation of live animals and their products are essential to safeguard the EU's consumers and its animal health status, and there is a large block of legislation covering import requirements. As there is free movement of goods once they enter the EU, this legislation is harmonised. Third countries must be approved and listed for the particular commodity. As a general rule, the EU is compliant with the OIE standards with respect to importations from third countries. Veterinary certification is required and, at a practical level, animals and their products from third countries may only enter the EU at approved border inspection posts (BIPs) where documentary and physical checks take place.

\subsubsection{Intra-EU Trade}

Rules for intra-EU trade of live animals require that an animal health certificate accompanies each consignment of animals, which is moved between member states or from a member state to a third country (Regulation (EU) 2016/429, Section 7). Operators have to notify each movement of live animals to the national competent authority (CA) in the member state of origin of the movement. Before the movement takes place, they have to enter data about the animals, itinerary and transport vehicle into the electronic data system Trade Control and Expert System (TRACES). The CA checks the provided notification data, an official veterinarian performs 
checks at the origin of the consignment prior to its departure to verify that animal health and welfare requirements are met, issues a health certificate in case requirements are met and/or performs non-discriminatory checks of the consignment at destination. The obligations vary depending on the species of animals or their products and the context of the movement. For example, the veterinary check at the location of origin is mandatory for animals moved for slaughter, but not needed in the case of day-old chicks. The costs of these activities related to the animal health check for animals for slaughter and day-old chicks were estimated between $€ 13$ million and $€ 33$ million per year (IBF et al. 2017). These costs are mainly made for pigs and poultry for slaughter and in the Netherlands and Germany, because the majority of consignments in the EU are for these animal species and originate in these member states.

\subsubsection{EU Finance for Animal Health}

The provisions for the management of the food chain expenditure under the Multiannual Financial Framework (MFF) 2014-2020 are laid down in Regulation (EU) No 652/2014. It covers the spending for animal health measures, plant health measures and official control activities, and establishes a common financial framework (CFF) for those areas. The CFF Regulation aims at modernising, simplifying and rationalising the previous financial and legal framework, adapting it to the requirements of the MFF 2014-2020. The CFF was designed as a part of the 'Smarter Rules for Safer Food Chain Package', which also included proposals for an EU Animal Health Law (AHL), an EU Plant Health Law, the regime for production and making available on the market of plant reproductive material and the rules which govern official controls.

At the moment of writing this chapter (May 2019) the Animal Health Law $^{1}$ (AHL) and Plant Health Law sectorial proposals have been adopted (for details on the plant health part, see Chap. 12). The general objective of the CFF is to contribute to a high level of health for humans, animals and plants along the food chain and in related areas, by preventing and eradicating diseases and pests and by ensuring a high level of protection

\footnotetext{
${ }^{1}$ Regulation (EU) 2016/429 of the European Parliament and of the Council of 9 March 2016 on transmissible animal diseases and amending and repealing certain acts in the area of animal health ('Animal Health Law') (Official Journal of the European Union, L 84, 31 March 2016).
} 
for consumers and the environment, while enhancing the competitiveness of the Union food and feed industry and favouring the creation of jobs. To achieve this objective, the CFF has a maximum total budget of almost $€ 1.9$ billion over seven years. It is mainly designed to support member states through grants that are co-funding certain measures in the field of animal health, plant health and official controls.

The CFF's four specific objectives correspond to each of the four policy areas referred to in the general objective: human health, animal health, plant health and official controls. They are accompanied by performance indicators for measuring the progress. Priorities for veterinary and phytosanitary programmes are laid down in Annex III to the Regulation itself, and provide the orientations for the above-mentioned programmes, to be further developed and updated annually (or multiannually) in the context of the specific work programmes. Annual or multiannual work programmes are also established for all measures covered by the CFF, except emergency measures and unexpected event.

The CFF co-funds measures related to:

veterinary eradication, control and surveillance programmes implemented by the member states, which are aimed to progressively eliminate animal diseases and to implement disease control measures: the EU financial contribution for veterinary programmes represent by far the largest amount of expenditure under the EU food safety budget;

veterinary and phytosanitary emergency measures, which are aimed to timely cope with emergency situations related to both animal health and plant health;

European reference laboratories activities, which are aimed to ensure high-quality, uniform testing in the EU and to support Commission activities on risk management and risk assessment in the area of laboratory analysis;

Better Training for Safer Food initiative, which is a training initiative addressing national authority staff involved in official controls in the areas of food and feed law, animal health and welfare and plant health rules;

coordinated control plans, which are organised on an ad hoc basis, in particular with a view of establishing the prevalence of hazards in feed, food or animals. 
In addition to the pre-existing measures, the CFF also co-funds phytosanitary survey programmes concerning the presence of pests in the Union territory, which involves surveillance measures preventing the introduction into the EU or the spread within the EU of harmful organisms considered to be the most dangerous or not known to occur in the Union territory. Table 11.2 provides an indicative overview of the allocation of the CFF budgets.

The provisions for emergency measures against 25 listed diseases of animals and fish are similar, save that $60 \%$ of costs are paid in the case of FMD but only $50 \%$ in the case of other diseases. The emergency measures funded by the CFF are for diseases that are required to be controlled by the destruction of affected animals, and include compensation paid to owners of animals killed for control purposes; costs of slaughter and disposal of carcases; costs of destroying contaminated animal products, feed and equipment; and costs of cleansing and disinfection. Payment from the CFF is subject to strict conditions of full compliance with EU animal health legislation and accurate accounting. Member states are seldom reimbursed fully for the claims they make. However, depending on the size of disease outbreaks in any year, the costs can be substantial. Table 11.3 shows the levels of payments from the CFF by disease for recent years. Bovine tuberculosis, rabies and salmonella are the diseases having the highest expenditure shares, together representing about two-third of the total annual expenditure on fighting of diseases.

The CFF also co-finances member states which claim for national schemes for the monitoring and eradication of certain diseases. Allocations are divided into three categories (I-III), where Category I, which attracts

Table 11.2 Forecast of annual budgets of CFF for the period 2014-2020

\begin{tabular}{lrrrrrrr}
\hline Year & 2014 & 2015 & 2016 & 2017 & 2018 & 2019 & 2020 \\
\hline $\begin{array}{l}\text { Eradication programmes and other } \\
\text { veterinary measures }\end{array}$ & 180.0 & 178.5 & 177.0 & 175.0 & 171.5 & 171.5 & 171.0 \\
$\begin{array}{l}\text { Plant health survey and seeds } \\
\text { Controls }\end{array}$ & 5.0 & 10.0 & 14.0 & 19.0 & 25.0 & 28.5 & 30.5 \\
$\begin{array}{l}\text { Animal health and plant health } \\
\text { emergency measures }\end{array}$ & 45.7 & 47.4 & 50.4 & 53.6 & 57.5 & 60.0 & 62.2 \\
$\begin{array}{l}\text { Support/administrative measures } \\
\text { Total }\end{array}$ & 20.0 & 20.0 & 20.0 & 20.0 & 20.0 & 20.0 & 20.0 \\
\hline
\end{tabular}

Source: EU Commission, DG SANTE, Unit D4—Food safety programme, emergency funding, 2017 
Table 11.3 Comparative table of CFF by disease (in 1000 euro)

\begin{tabular}{lrrrr}
\hline Disease & \multicolumn{1}{c}{2015} & \multicolumn{1}{c}{2016} & \multicolumn{1}{c}{2017} & \multicolumn{1}{c}{$\begin{array}{c}\text { Average share } \\
(\%)\end{array}$} \\
\hline Classical swine fever & 2324 & 2553 & 1967 & 1.51 \\
Avian influenza & 2111 & 2065 & 2048 & 1.37 \\
Bluetongue & 6281 & 6730 & 7997 & 4.63 \\
Transmissible spongiform & 14,155 & 11,797 & 9329 & 7.79 \\
encephalopathies & & & & \\
Sheep and goat brucellosis & 11,798 & 12,228 & 9383 & 7.36 \\
Bovine brucellosis & 10,901 & 10,312 & 9556 & 6.79 \\
African swine fever & 2663 & 7572 & 9638 & 4.36 \\
Salmonella & 15,972 & 19,956 & 18,954 & 12.08 \\
Rabies & 16,777 & 21,376 & 24,955 & 13.90 \\
Bovine tuberculosis & 64,024 & 61,934 & 55,962 & 40.13 \\
Total & 147,317 & 156,523 & 149,789 & 100.00
\end{tabular}

Source: EU Commission, DG SANTE, Unit D4—Food safety programme, emergency funding, 2017 and 2018

over $96 \%$ of the available funding, is for animal diseases which have a significant impact on public health, including transmissible spongiform encephalopathies such as BSE. Category II includes some of the original OIE List A diseases, and Category III some diseases originally on OIE List B. In 2017 the CFF allocated approximately $€ 150$ million to these schemes. The CFF also makes contributions-of approximately $€ 2.5$ million each year - to the funding of designated community reference laboratories (CRLs), recognised as centres of excellence in member states for the diagnosis of specific animal diseases in the EU and the provision of expert advice.

\subsection{EU Animal Health Legislation}

At the end of 2004, the European Commission launched a root-andbranch independent review of the EU animal health policy. The review covered what had been achieved in the past, how well it had been achieved and how policy should develop in the future. There were a number of drivers for a review. Much of the existing policy had been developed in a piecemeal fashion between 1988 and 1995 when there were only 12 member states. Legislation had been made in haste, usually in response to a disease crisis. New and emerging diseases such as severe acute respiratory syndrome (SARS), and Hendra and Nipah viruses had arisen which were 
zoonotic and which had originated from wildlife reservoirs. There was concern over the global spread of a strain of avian influenza ( $\mathrm{H} 5 \mathrm{Nl}$ ) which was zoonotic and killed over $50 \%$ of those human beings unfortunate enough to become infected. With globalisation of trade, the volume of trade in animal products within the EU and with third-country trading partners had increased substantially.

During the preceding decade, the EU had suffered large and very costly epidemics of disease: classical swine fever (CSF), foot and mouth disease (FMD) and highly pathogenic avian influenza (HPAI). In the face of these large outbreaks, there was growing public concern as to whether killing of large numbers of animals in order to control disease was the right approach. This concern was greatest in a sector of the EU which had grown with increasing affluence and which kept livestock not for commercial reasons but as a hobby. Hobby keepers often place an emotional value on their livestock beyond any commercial value, which was the basis of compensation in any disease eradication programme. Also, the institutional framework of the EU had changed, and there had been significant advances in the science and technology needed to inform animal health policy. Once the review had been completed, there was an extensive stakeholder consultation following which the Commission published a Communication: 'A new Animal Health Strategy for the European Union (2007-2013) where Prevention is better than cure' (European Commission 2007), otherwise known as the EU Animal Health Strategy 2007-2013.

A European Court of Auditors (2004) special report on the eradication, control and monitoring programmes to contain animal diseases, concluded that the animal disease programmes adequately contained animal diseases, and that the Commission's approach is supported by good technical advice, risk analysis and a mechanism for prioritising resources (ECA 2016). A noted drawback is that it is difficult to evaluate the cost-effectiveness (CE) of programmes due to the lack of available models and standardised for such an analysis. For veterinary programmes, unit costs and ceilings are used as a financial compensation system. These contribute to a lower administrative burden for DG SANTE as well as for member states. Although it takes a long time to identify and agree unit costs and ceilings, once established they create clarity and transparency in funding. To date, unit costs and ceilings have not been used for other spending areas within the CFF, but might well be considered. An observation made by the ECA is that the exchange of epidemiological information and the ready access to historic results could be better supported by relevant information systems. 


\subsubsection{EU Animal Health Strategy 2007-2013 'Prevention Is Better Than Cure'}

The Strategy was a six-year work programme with four high-level goals:

To ensure a high level of public health and food safety by minimising the incidence of animal diseases, food-borne diseases and biotoxins, and chemical risks to humans

To promote animal health by preventing/reducing the incidence of animal diseases and in this way support the rural economy

To improve economic growth/cohesion/competitiveness by assuring free circulation of goods and animal movements proportionate to the risk of spreading disease and to the welfare of transported animals

To promote farming practices and animal welfare which prevent threats related to animal health and minimise environmental impacts in support of the EU Sustainable Development Strategy

The work programme was set out in the Action Plan for the implementation of the EU Animal Health Strategy (European Commission 2008). It was divided into four pillars of work:

Prioritisation of EU intervention

The EU animal health framework

Prevention, surveillance and preparedness

Science, innovation and research

These points (also called the four pillars) are briefly described below.

\subsubsection{Prioritisation of EU Intervention}

Pillar 1 of the strategy promises the use of risk assessment and risk management to identify threats relevant to the four high-level goals of the Strategy, to determine the level of acceptable risk to the EU and, since resources are limited, to prioritise the actions to be taken. Cost-benefit analysis and an assessment of likely effectiveness of any proposed action will be used to prioritise and determine any interventions. Decisions will be based on sound science. History has shown that there will always be new and emerging animal diseases. Where a new threat has been identified but there is scientific uncertainty about the likelihood of it occurring, the 
precautionary principle will be applied,; that is, proportionate and provisional measures will be adopted to ensure a high level of health protection pending further scientific information. While a sensible ideal, it will be interesting to see how the politicians in member states are prepared to apply the precautionary principle in the face of a new threat to public health from a disease of animal origin, which causes severe disease or death in human beings. In the face of uncertainty, politicians have tended to overreact, and behaviour towards animal health-related risks varies between member states.

\subsubsection{A Modern EU Animal Health Framework}

There are a number of strands to pillar 2 of the strategy. For good reason, EU animal health policy has historically evolved in a piecemeal fashion. The plan was to have a single horizontal legal framework which will define and integrate common principles and requirements of existing legislation including import controls, intra-EU trade, animal disease control, animal nutrition and animal welfare (see below how this has been achieved via the Animal Health Law). The plan is to simplify existing legislation and replace it by the new framework and convergence with international standards (OIE/Codex standards).

Developing efficient cost and responsibility sharing schemes is a further strand of pillar 2. Based on past experiences, it was felt that if livestock keepers contributed to the costs of an outbreak, they would take more responsibility with respect to prevention by practising good biosecurity. The costs of EU disease control in the enlarged EU and potential future costs of epidemics was an important driver in any cost and responsibility sharing initiative. The practical difficulties of implementing an EU-wide cost and responsibility sharing initiative should not be underestimated. There is a diverse range of views amongst member states, from some that have already a levy system in place, to others that require private insurance to top-up compensation, and yet others that believe that, as livestock keepers suffer consequential loss, this should be their only contribution to cost sharing.

\subsubsection{Threat Prevention, Surveillance and Crisis Prevention}

Pillar 3 of the strategy covers supporting on-farm biosecurity measures, which are the other side of the cost and responsibility sharing coin. The outcome will be the issuance of EU guidance and possible funding of infrastructure to support on-farm biosecurity. 
However, as the costs of operating biosecurity measures becomes greater due to the increasing risk of disease introduction, there will be mounting pressure to become more proactive and to cooperate with third countries to stop new diseases at their source, and ultimately to achieve freedom from introduced animal diseases through building in resistance and resilience. New science (pillar 4) with advances in detection, monitoring and modelling of biosecurity threats will be an important feature of this inevitable evolution of biosecurity systems.

Pillar 3 also covers identification and tracing (essential for disease control), traceability of food for human consumption, better border biosecurity, and surveillance and crisis preparedness. Part of the identification of animals is the identification and registration of animals at farm level, which is also supported by the Common Agricultural Policy (CAP) via its crosscompliance mechanism. Veterinary surveillance is an essential component of any animal health strategy. In the case of epidemic diseases such as FMD, early detection is key to rapid implementation of control measures and to limiting the eventual size of an epidemic. In the case of insidious diseases such as salmonellosis, tuberculosis and brucellosis, a programme of laboratory testing is required to detect disease. Surveillance can be costly and hence the strategy requires prioritisation as in pillar 1 . The need for each member state to have detailed contingency plans to deal with incursions of animal disease, tested through regular exercises, was a lesson learnt from the FMD crisis of 2001.

\subsubsection{Science, Innovation and Research}

Pillar 4 has the objective of stimulating and coordinating risk analysis, science, innovation and research contributing to a high level of public health and to the competitiveness of EU animal health business. Innovative developments may well provide alternative approaches to disease control within the EU and remove the need to control some diseases by mass killing of affected animals.

One of the key outputs of the Animal Health Strategy 2007-2013 'Prevention is better than cure' is the Animal Health Law which was introduced in 2016.

\subsubsection{EU Animal Health Law (Regulation (EU) 2016/429)}

The European Parliament and the Council adopted Regulation (EU) $2016 / 429$ on transmissible animal diseases ('Animal Health Law') in 
March 2016. The AHL will apply in all EU member states from 21 April 2021. The Animal Health Law is part of a package of measures proposed by the Commission in May 2013 to strengthen the enforcement of health and safety standards for the whole agri-food chain. This Regulation is about animal diseases that are transmissible to animals or humans. It provides for principles and rules for the prevention and control of such animal diseases in kept animals (i.e. animals under human control) and wild animals and animal products. It covers both terrestrial and aquatic animals. More precisely, these rules consist of requirements for disease prevention and preparedness; disease awareness; biosecurity; traceability of animals and where necessary products thereof; intra-EU movements and entry into the EU of animals and animal products; surveillance; disease control and eradication; and emergency measures.

Overall, the single, comprehensive Animal Health Law will support the EU livestock sector in its quest towards competitiveness and safe and smooth EU market of animals and of their products, leading to growth and jobs in this important sector:

The huge number of legal acts are streamlined into a single law

Simpler and clearer rules enable authorities and those having to follow the rules to focus on key priorities: preventing and eradicating disease

Responsibilities are clarified for farmers, vets and others dealing with animals

The new rules allow greater use of new technologies for animal health activities - surveillance of pathogens, electronic identification and registration of animals

Better early detection and control of animal diseases, including emerging diseases linked to climate change, will help to reduce the occurrence and effects of animal epidemics

There will be more flexibility to adjust rules to local circumstances, and to emerging issues such as climate and social change

It sets out a better legal basis for monitoring animal pathogens resistant to antimicrobial agents supplementing existing rules and two other proposals currently being negotiated in the European Parliament and Council, on veterinary medicines and on medicated feed

Several delegated and implementing acts have been adopted by the Commission until April 2019 to make the new rules applicable. 


\subsection{Economic Assessment of Animal Health Programmes}

As discussed above in the EU's Animal Health Strategy, a reference to economic aspects is made in pillars 1 (cost sharing) and 2 (costeffectiveness). Cost-effectiveness (CE) analysis is a tool to relate outputs or impacts of an intervention to its costs. CE analyses have been widely applied in the human health domain, but are less frequent in the animal health field (Martins and Rushton 2014).

$\mathrm{CE}$ analyses are mostly done ex ante, to help set priorities for the funding of health care and food safety programmes or evaluate different alternative strategies. The essence is that for each intervention, the costs associated with that strategy can be compared with an alternative strategy aimed at contributing to the same objective. In this regard, the full set of interventions, measures or programmes covered by the common financial framework associated with Regulation (EU) 652/2014, as well as the objective of the evaluation, are important. An ex post evaluation can be done to evaluate the effect of a strategy.

From a CE perspective the objective of such an evaluation could be still formulated in different ways. For example:

to get an indication of the added value of the EU contribution

to compare additions to intervention strategies

to compare approaches between different MSs (e.g. in case study analyses) to get an insight into the effectiveness of allocation of budget amongst different alternatives within or between EU policy areas

In case an intervention results in improved outputs or impact (effect), but at the same time the costs increase, the incremental cost approach to $\mathrm{CE}$ is useful and incremental CE ratios for various interventions or programmes can be ranked to set funding priorities.

\subsubsection{Cost-Effectiveness Ratio}

Cost-effectiveness (CE) analysis is a tool to relate outputs or impacts of an intervention to its costs. Its basic form is: 


$$
\mathrm{CE}=\frac{\text { cost of intervention }}{\text { effectiveness of intervention }}
$$

CE ratios can be presented as an average ratio (see expression above), but also as an incremental cost-effectiveness ratio where different intervention alternatives are compared. The basic structure of an incremental $\mathrm{CE}$ ratio (iCE) is:

$$
\mathrm{iCE}=\frac{\text { cost of intervention } \mathrm{A}-\text { cost of intervention } \mathrm{B}}{\text { effect of intervention } \mathrm{A}-\text { effect of intervention } \mathrm{B}}
$$

See, for example, Detsky and Nagly (1990) for a worked-out example.

\subsubsection{Steps in a Cost-Effectiveness Analysis}

CE analysis involves a number of steps (Martins and Rushton 2014), which are briefly described here (see Fig. 11.1 for a schematic overview).

Firstly, CE analysis always requires a perspective or viewpoint from which the analysis is pursued. Roughly speaking, the two options are here the programme option and the societal option.

The next step regards the identification of the problem and the link with the intervention. The identification step may, for example, be based on the intervention logic of the CFF Regulation. In the proposed CE analysis, appropriate levels of analysis will have to be chosen, which allow for a meaningful use of the CE indicators.

The third step, which is closely connected with the previous one, involves the determination of a conceptual model, which further describes the mechanisms that play a role in the defined problem domain, and outlines the full range of events arising from the intervention. To do this often, a decision tree approach is chosen (Pettiti 2000). This is the step which provides insight into the linkage between inputs (efforts, costs) and outputs (results, impacts). Having clarity on this, the next steps are to further identify and estimate the costs and the outputs.

As regards the costs (representing the numerator part of the CE ratio), this first includes an estimate of the costs of all the goods, services and other resources that are consumed in the provision of the analysed intervention. Second, costs can also arise because of side effects and present and future consequences associated with the analysed policy intervention 


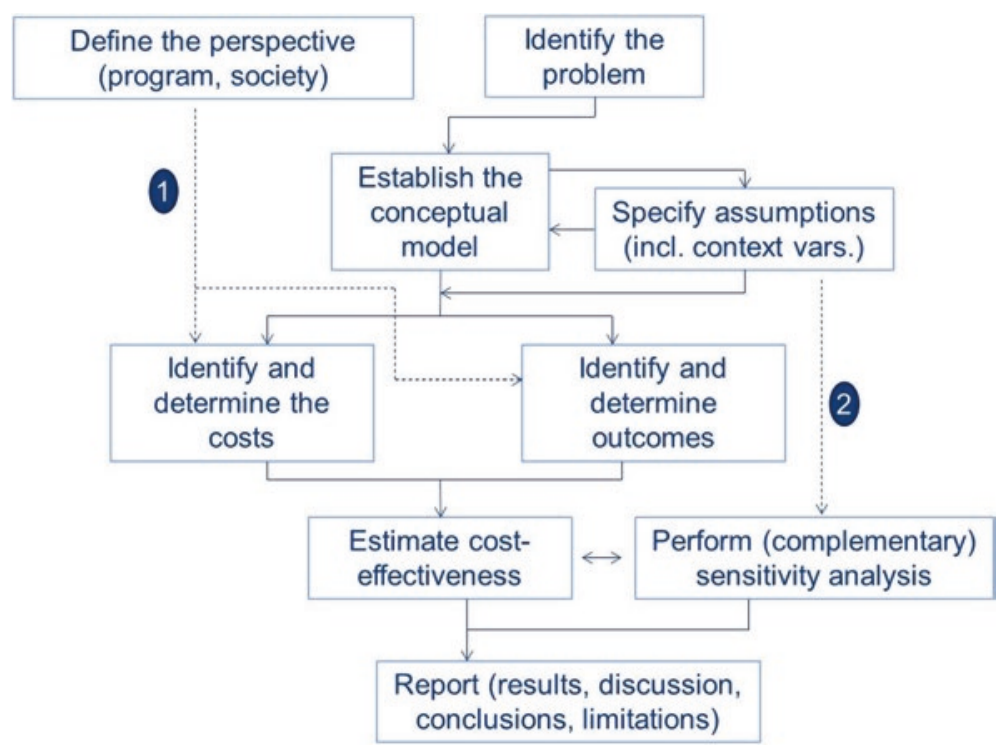

Fig. 11.1 Steps in a CE analysis. (Source: Adapted from Martins and Rushton 2014)

(e.g. indirect and aftermath costs related to a disease outbreak that has been successfully addressed by an emergency intervention policy measure) (Siegel et al. 1996). In the health literature it is a usual practice to focus on the direct costs of the intervention or policy measure analysed. Often guidelines are used, which clearly establish the categories of costs that should be considered as direct costs. They include categories like costs of tests, medicines, labour costs arising from intervention-related activities, such as surveillance and monitoring efforts, disease eradication actions (e.g. slaughtering of animals).

In order to estimate the effectiveness of the intervention (representing the denominator part of the $\mathrm{CE}$ ratio), a vast range of measures is used in the literature, which reflects the diversity of effects associated with the typical kind of policy intervention measures in this domain. Effectiveness estimate measures include premature deaths averted, change in life expectancy, improvement in the years of potential life gained (YLGs), quality of life years (QALYs), disability-adjusted life years (DALYs) (Brazier et al. 2007; Boardman et al. 2014), reductions in the number of disease cases, 
prevalence, risk on disease outbreak (e.g. due to a prevention programme) and so on. Effectiveness can be estimated by measuring the results of an intervention, as well as by measuring the impact of an intervention. Measurement of the full impact might be often difficult (e.g. how to measure the impact of an improved health status on the gains this created with respect to a country's trade position, such as being less vulnerable to an export ban). The estimation of effect may require the use of an epidemiological model tailored to the policy intervention or project environment that is analysed (e.g. Bergevoet et al. 2009). The difficulties with respect to impact assessment does not preclude the use of CE indicators, since reliable output indicators will be usually available (Brent 2003).

Having the information from steps (4) and (5), the CE ratio can be calculated as presented before (by putting the appropriate numbers in the denominator and the numerator of the CE ratio expression). As has been denoted, $\mathrm{CE}$ analysis always implies that a number of assumptions have to be made, which will influence the outcome of the CE indicator. Sensitivity analysis may be used to analyse how sensitive the CE indicator is with respect to specific assumptions that are made and by that provide the analyst and client insight into a reliable range of the $\mathrm{CE}$ indicator.

The final step concerns the proper reporting of the analysis and outcomes, which presents the CE results, how they are affected by the different components underlying them, the assumptions they are based on, and the limitations inherent to the analysis (e.g. the potential role of context or confounding variables).

\subsubsection{Complexities in Animal Health Programme Assessments}

The CE results are sensitive to the time horizon of the analysis. For that reason, it is important to cover the appropriate (or entire) time on which the analysed intervention has its impact (Brent 2003; Cohen and Reynolds 2008). Similar to the standard approach in cost/benefit analysis, when costs are spread over time, these should be properly discounted to allow for a proper aggregation (net present value-calculation). ${ }^{2}$ As an example,

\footnotetext{
${ }^{2}$ Note that while costs are expressed in monetary units and easily can be aggregated, effects are measured in their own (physical) non-monetary units. However, this does not preclude the discounting of the effects when they occur at different moments over time. Moreover, an argument could be made to use consistent discount rates when discounting costs and effect rather than treating both differently.
} 
in case of an emergency (disease outbreak), it is likely that costs associated with an emergency payment measure not only concern outbreak period, but that also payments are made in later periods. Costs and effects of interventions need to be carefully related to each other, and then proper aggregation of costs and effects need to be accounted for, including discounting (Brent 2003, chapter 6). To establish this linkage in the literature frequently epidemiological-economic models are used, which not only enable the linkage of costs to final impacts, but also allow to account for the role of control or context variables.

For the evaluation of health policy measures or projects, as for any other kind of project, not only the objectives (see Fig. 11.1) but also the baseline and other alternatives have to be identified. The baseline or benchmark choice co-depends on the scope of the evaluation. In case the alternative of having the current or evaluated policy would be discontinuing the policy or have no policy intervention at all, the without intervention measure or project alternative is an obvious candidate to use as a benchmark. For each (other) alternative, then the incremental costs and effects relative to this benchmark are identified and determined. The benchmark choice is an important issue, and it should be realistic.

Most CE analyses described in the literature are so-called ex ante studies. The CE technique is helpful in evaluating different alternatives or strategies. As was mentioned before, most of the time the analysis is supported by epidemiological models that simulate expected effects given a specific strategy. Sensitivity analyses in such evaluations should also indicate when an alternative strategy should be preferred. In the ex post monitoring, the main focus could then be to monitor whether key indicators are reaching tipping points so alternative strategies need to be considered. A complicating factor in ex post CE analysis is that the control or context variables are no longer constant (in contrast with ex ante $\mathrm{CE}$ analysis using modelling tools in which these variables are controlled), but are changing at the same time as the intervention efforts are made (and maybe in different directions for different member states). As such, this likely affects the linkage between the intervention and the final impact, and for a sound CE analysis the impact of the change in context variables on the programme performance need to be corrected for. The reason why in the literature ex post evaluations are relatively scarce is probably because of the many complexities involved and because CE analysis is especially interesting when comparing different alternatives. Once a strategy is chosen for implemen- 
tation (as is the case in an ex post situation) comparison with (hypothetical) alternatives (that could have been chosen) is often of less interest.

It should be mentioned that at this moment there are already two approaches followed by DG SANTE to guarantee objective-oriented policy measures and preserve resource efficiency. First, the set of operational indicators that has been developed has a clear link with the (specific) objectives as they are defined in Regulation (EU) No 652/2014, and which thus allow to monitor performance in this regard. Though improvements might be possible, this is an important input for the impact evaluation of the policy. Second, DG SANTE uses an extensive so-called fee-grid approach, which defines eligible unit cost levels or imposes maximum limits to unit costs for different (disease-specific) eligible cost categories. These per unit cost indicators are simple cost/output indicators which have clear limitations, but are nevertheless second best instruments to monitor efficiency with respect to resource use.

\subsection{Conclusions}

The EU's animal health policy helps to protect more than 500 million consumers in the EU and facilitates the functioning of agri-food supply chains. The competitive position of this sector is supported by the EU's high food safety standards, which contribute to a global perception of high-quality European products.

The European Court of Auditors (2004) concluded that the animal disease programmes adequately contained animal diseases, and that the Commission's approach is supported by good technical advice, risk analysis and a mechanism for prioritising resources. Serious animal health diseases have been brought under control or have been eradicated, allowing the production of safe, wholesome food within the EU. Notable successes of the policy are the decreases in cases of BSE in cattle, salmonella in poultry and rabies in wildlife. However, the EU continues to remain under the threat of exotic animal diseases and will continue to do so as new animal diseases emerge. As an example, the eradication of ASF, bovine brucellosis and tuberculosis and ovine and caprine brucellosis are posing continuing challenges in some member states.

The CFF contributes to achieving and supporting EU added value. Member states benefit from the prioritised and targeted implementation of EU co-funded activities, especially for emergency, eradication, control and monitoring measures for animal diseases and plant pest throughout 
the Union. The financial solidarity that the CFF provides enables member states to take required actions according to their interests. Otherwise these may have been beyond the (financial) capacity of an individual member state. Moreover, the CFF enables harmonised and robust controls, which satisfy an important need with respect to an effective food safety policy.

In the last half century, the EU has come a long way towards achieving a fully harmonised legal framework for the importation and trade of live animals and animal products. With the new Animal Health Law, which was adopted in 2016, the EU has made a single, comprehensive animal health regulation to further strengthen the enforcement of health standards for the whole agri-food chain. Until April 2019, delegated and implementing acts have been adopted by the Commission to make the new rules applicable. This comprehensive Animal Health Law also aims to support the EU livestock sector in its quest towards competitiveness and safe and smooth EU market of animals and of their products.

\section{REFERENCES}

Bergevoet, R.H., G. van Schaik, J. Veling, G.B. Backus, and P. Franken. 2009. Economic and Epidemiological Evaluation of Salmonella Control in Dutch Dairy Herds. Preventive Veterinary Medicine 89 (1-2): 1-7.

Boardman, A.E., D.H. Greenberg, A.R. Vining, and D.L. Weimer. 2014. CostBenefit Analysis: Concepts and Practice. 4th ed. Upper Saddle River: Pearson Education.

Brazier, J., J. Ratcliffe, A. Tsuchiya, and J. Salomon. 2007. Measuring an Valuing Health Benefits for Economic Evaluation. New York: Oxford University Press.

Brent, R.J. 2003. Cost-Benefit Analysis and Health Care Evaluations. Cheltenham: Edward Elgar.

Cohen, D.J., and M.R. Reynolds. 2008. Interpreting the Results of CostEffectiveness Studies. Journal of the American College of Cardiology 52 (25): $2119-2126$.

Court of Auditors. 2004. Special Report No 8/2004. Official Journal of the European Union. Special Report. OJ 2005/C 54/01.

Detsky, A.S., and I.G. Nagly. 1990. A Clinician's Guide to Cost-Effectiveness Analysis. Annals of Internal Medicine 113: 147-154.

ECA. 2016. Eradication, Control and Monitoring Programmes to Contain Animal Diseases (Special Report). Luxembourg: European Union.

European Commission. 2007. A New Animal Health Strategy for the European Union (2007-2013) Where Prevention Is Better Than Cure. Brussels: European 
Commission, Communication COM 539 (2007). http://ec.europa.eu/food/ animal/diseases/strategy/animal_health_strategy_en.pdf

. 2008. Action Plan for the Implementation of the EU Animal Health Strategy. Brussels: European Commission, Communication COM 545 (2008), Brussels. http://www.eubusiness.com/topics/agri/animal-health-guide.03/

IBF International Consulting, WUR, VetEffecT, and European Commission. 2017. Study on intra-European Union (intra-EU) Animal Health Certification of Certain Live Animals. Publications Office of the European Union, Luxembourg, ISBN 978-92-79-73525-7, https://doi.org/10.2875/809481. Martins, S.B., and J. Rushton. 2014. Cost-Effectiveness Analysis: Adding Value to Assessment of Animal Health, Welfare and Production. Revue scientifique et technique-Office international des épizooties 33 (3): 1-18.

Pettiti, D.B. 2000. Meta-Analysis, Decision-Analysis, and Cost-Effectiveness Analysis - Methods for Quantitative Synthesis in Medicine. 2nd ed. New York: Oxford University Press. (Monographs in Epidemiology and Biostatistics No. 31).

Siegel, J.E., M.C. Weinstein, L.B. Russell, and M.R. Gold. 1996. Recommendations for Reporting Cost-Effectiveness Analyses. JAMA 276 (16): 1339-1341. https://doi.org/10.1001/jama.1996.03540160061034. 